Document downloaded from:

http://hdl.handle.net/10251/77200

This paper must be cited as:

Heredia Gutiérrez, AB.; Castelló Gómez, ML.; Argüelles Foix, AL.; Andrés Grau, AM. (2014). Evolution of mechanical and optical properties of french fries obtained by hot air-frying. LWT - Food Science and Technology. 57(2):755-760. doi:10.1016/j.Iwt.2014.02.038.

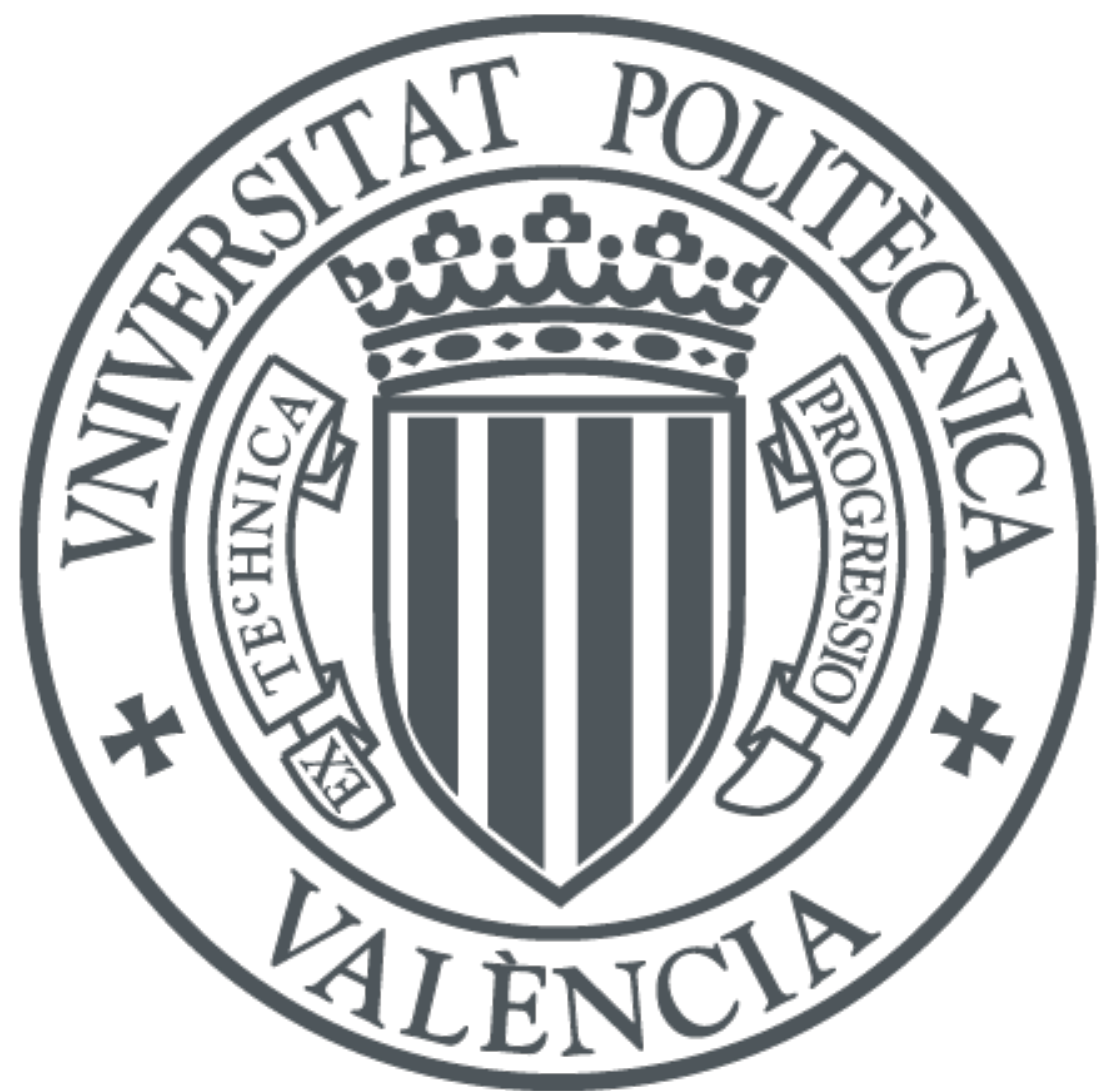

The final publication is available at

https://dx.doi.org/10.1016/j.Iwt.2014.02.038

Copyright Elsevier

Additional Information 


\section{EVOLUTION OF MECHANICAL AND OPTICAL PROPERTIES OF FRENCH FRIES OBTAINED BY AIR- FRYING}

Heredia, A., Castelló, M.L. Argüelles, A., Andrés, A. Institute of Food Engineering Research for Development. Universitat Politècnica de València. Camino de Vera s/n, 46022. Valencia. Spain. Corresponding author: Tel. +34963873652; E-mail address: anhegu@tal.upv.es

\section{Abstract}

The aim of this study was to analyse the influence of frying technique (air-frying and deep oil-frying) and type of pre-treatment (freezing and blanching) on the evolution of mechanical and optical properties of French fries. The results showed that the chromatic parameters, $a{ }^{*}$ and $b$ *, experimented an increase regardless of the frying method; while the increase in a * was significantly higher in deep-oil frying as a result of Maillard's reactions. The texture analysis reported a first stage of initial softening related to starch gelatinization followed by a second stage where the maximum force increased due to the gradual formation of a crust, both stages being faster in deep-oil frying. Pre-frozen potatoes presented the highest value of maximum force parameter independent of the type of frying.

Keywords: air-frying; French fries; texture; colour

\section{Introduction}

Nowadays, fried products are very popular with people of all ages. Their preparation is easy, fast and economical. For these reasons, in recent decades, frying processes have been generalized not only in fast food establishments but also in restaurants, food industries (for example snacks), homes, etc. Among all commonly fried products, 
French fries are the most important due to their high consumption and production (Garayo \& Moreira, 2002).

The deep-oil frying process is one of the oldest techniques of preparing food, which is highly appreciated by consumers due to the taste. This process basically consists of an immersion of the product in hot vegetable oil, causing the egress of water and the ingress of oil in the product with the consequent changes in texture and colour properties. The product becomes crusty due to the loss of water and acquires a light brown colour due to Maillard's reactions consisting of high temperature reactions between reducing sugars (glucose and fructose) and amino acids such as asparagine. The main disadvantage of traditional French fries consumption, and in general all deepoil fried products, is related to their high levels of fat (around 35.3-44.5\%) (Garayo \& Moreira, 2002), since consumers are more and more concerned about health. It is known that a high fat diet is one of the major factors causing an increase in the incidence of cardiovascular disease (Moreira \& Barrufet, 1998; Ni \& Datta, 1999). Because of this, much research has been aimed towards the development of fried food products with reduced fat. Consequently, many studies on the mechanisms of fat absorption during frying have been carried out considering different pretreatment and deep-oil frying conditions (Aguilera \& Gloria-Hernández, 2000; Mai Tran, Dong Chen \& Southern, 2007; Debnath, Rastogi, Krishna \& Lokesh, 2009; Dueik, Robert \& Bouchon, 2010). Air-frying is a new way to obtain fried products by means of an emulsion of oil drops in a hot air stream. The process takes place in a chamber in which the product is continuously in movement to promote the homogenous contact between the product and the external emulsion medium. In this way, the product is being gradually dehydrated while the typical crust on fried products appears. Under air-frying conditions, the final product exhibits $80 \%$ lower oil content than traditional frying (Heredia, Castelló \& Andrés, 2010). However the lower oil content could affect several sensory aspects of the product such as crust formation, palatability, colour, brightness, 
etc. Therefore it is important to evaluate the influence of the above-mentioned strategies, focusing on the effect of reducing oil on sensory characteristics.

Moreover, there are several pretreatments that can be applied to products before frying in order to improve the process or mainly to extend the shelf life of the raw material and provide enough supplies to food industry, restaurants or homes. Thus, potatoes or coated products can be fried when they are fresh or when they have been previously frozen (Mateos, 2003). This freezing pretreatment allows the consumer to have the product ready to be prepared avoiding the previous stages of pealing, cleaning, cutting, etc. to directly fry these products. This is very usual in pre-fried potatoes (Mateos, 2003). Other common pretreatments in potatoes sticks are blanching, air drying, microwave application, osmotic treatment, etc. (Liu \& Scanlon, 2007; Song, Zhang, \& Mujumdar, 2007; Krokida, Oreopoulou, Maroulis \& Marinos-Kouris (2001a)). These pretreatments affect the final quality of the French fries, especially in terms of mechanical and optical properties and the amount of oil in the final product. In this sense, Krokida, Oreopoulou, Maroulis \& Marinos-Kouris (2001b) observed that both blanching and air dehydration led to reduce oil absorption.

Another important aspect to bear in mind in French fries is the presence of acrylamide. This is a normal component generated in fried products as an intermediate of the Maillard's reactions due to a reaction between reducing sugars, the amino acid asparigine (Gökmen, Palazoglu, \& Senyuva, 2006) and the intense heat treatment applied (Amrein, Schönbächler, Escher \& Amadò, 2004; Taubert, Harlfinger, Henkes, Berkels, \& Schomig, 2004; Gökmen \& Senyuva, 2007). At high levels it is considered to be toxic, being a possible carcinogen for humans (group $2 \mathrm{~A}$ ) by the International Agency of Research of Cancer (IARC, 1999). A blanching pretreatment of potatoes with water at $90^{\circ} \mathrm{C}$ seems to be the best way to reduce the amount of acrylamide in the final fried potato due to a leakage of reducing sugars (Haase, Matthaus, \& Vosmann, 2003; Pedreschi, Moyano, Kaack \& Gramby, 2005). Moreover, the acrylamide formation seems to be related with the level of browning in the products according to 
different authors (Moyano, Ríoseco, \& González, 2002; Pedreschi, Kaack \& Granby, 2006). They observed that there was a relation between the amount of acrylamide and the increase in the coordinate $\mathrm{a}^{*}$ and consequently, this colour coordinate could be considered a good indicator of the acrylamide content.

For all the reasons explained, the aim of this work is to analyze the evolution of the mechanical and optical properties of French fries obtained by air-hot frying in comparison with those obtained by deep oil frying. The effect of the application of a pretreatment (freezing or blanching) was also analysed.

\section{Materials and methods}

\subsection{Raw material}

Fresh potatoes (Solanum tuberosum L., Mona Lisa variety) were washed, sorted, peeled and cut into $0.009 \mathrm{~m} \times 0.009 \mathrm{~m} \times 0.03 \mathrm{~m}$ strips with a manual cutter. The frying process, either deep-oil or hot-air frying, was carried out on (i) control or unpretreated strips, (ii) strips blanched in hot water at $90{ }^{\circ} \mathrm{C}$ for $1 \mathrm{~min}$, and (iii) commercial frozen pre-fried French fries (strips $0.009 \mathrm{~m} \times 0.009 \mathrm{~m} \times 0.03 \mathrm{~m}$ ) with an initial fat content of 3 $\%$. Refined seed oil with $0.2^{\circ}$ acidity was used to fry the potatoes.

\subsection{Methodology and Equipment}

Experiments were carried out at a fixed frying temperature of $180^{\circ} \mathrm{C}$ in commercial deep oil-frying (Solac) and hot air-frying (Actifry, Tefal) equipment. For the deep-oil experiments, samples were immersed in $2 \mathrm{~L}$ of oil per $\mathrm{kg}$ of potato according to the capacity of the equipment; while $0.003 \mathrm{~kg}$ of oil per $\mathrm{kg}$ of potatoes was added to the chamber according to the specifications of the hot-air frying equipment. Three samples were removed from the frying equipment at $3 \mathrm{~min}$ intervals for hot air-frying 
111 experiments (total processing time: $30 \mathrm{~min}$ ) and 2 min intervals (total processing time:

$11216 \mathrm{~min}$ ) for deep-oil frying for analytical determinations.

\subsection{Analytical Determinations}

115

2.3.1. Mechanical properties

The mechanical properties of the potato strips for each kind of frying and pre-treatment at different times of the process were analysed using a universal texture analyzer (TA/XT/PLUS Stable Micro. Systems Ltd., Godalming, UK) by means of a puncture test (2 mm diameter punch) (Bourne, 2002). The assay was carried out till the sample was completely pierced. Samples were analysed when they reached a normal consumption temperature $\left(50^{\circ} \mathrm{C}\right)$. Three replicates were performed for each treatment. The analyzed parameter was the initial maximum force $\left(F_{\max }\right)$ expressed in $\mathrm{N}$.

\subsubsection{Optical properties}

127

The colour analysis of potato strips was measured by means of a Minolta (CM-3600d) spectrocolorimeter with a $7 \mathrm{~mm}$ diameter lens. CIE-L*a*b* coordinates were obtained using D65 illuminant and 10o observer as a reference system. Coordinates in the CIE$L^{*} a^{*} b^{*}$ colour space were obtained from the absorption spectrum between 380 and 770 $\mathrm{nm}$.

The CIE- $L^{*} a^{*} b^{*}$ system is composed of: luminosity $\left(L^{*}\right)$, red-green variation $\left(a^{*}\right)$, yellow-blue variation $\left(b^{*}\right)$. Moreover, from coordinates $a^{*}$ and $b^{*}$ polar coordinates purity of colour or chrome $\left(\mathrm{C}^{*}\right)$ and hue $\left(\mathrm{h}^{*}\right)$ can be obtained by means of the following equations:

$$
C^{*}=\sqrt{a^{*^{2}+b^{* 2}}}
$$




$$
h^{*}=\operatorname{arctg} \frac{a^{*}}{b^{*}}
$$

Measurements were carried out on two of the four sides of each potato strip. No differences in the spectrum were found when black or white background was used to measure the colour of the samples, so measurements were carried out only using a black background. For each potato pretreatment, type, and time of frying, three replicates were performed.

\section{Results and discussion}

147 Colour measurement could be a good way to control some parameters or characteristics of the products difficult to quantify by other procedures. Heat and mass transfers during frying cause physicochemical changes affecting the colour of fried products. These phenomena are conditioned by process variables such as oil type and temperature, frying time, applied pretreatments or the dimensions of the product (Krokida, Oreopoulou, Maroulis \& Marinos-Kouris, 2001c). Table 1 shows the colour coordinates of the system $\mathrm{CIEL}^{*} \mathrm{a}^{*} \mathrm{~b}^{*}$ and also chrome $\left(\mathrm{C}^{*}\right)$ and hue $\left(\mathrm{h}^{\star}\right)$ of raw, frozen or blanched potato strips at the beginning of the treatment. According to these results, blanching pre-treatment mainly caused a luminosity loss and a decrease in the $b^{*}$ coordinate. This fact implied an increase in opacity along with a decrease in purity of colour and hue. On the other hand, frozen samples showed the highest luminosity value.

Figure 1 shows the evolution of $L^{*}$ during both types of frying, with respect to the initial values $\left(\mathrm{L}^{*}{ }_{0}\right)$. As can be observed, the type of frying affects this parameter differently. Deep-oil frying induced a luminosity loss in frozen samples and with more frying time than unpretreated ones; while a null variation of this parameter was detected during hot air frying in unpretreated and frozen samples. In the blanched samples and those fried in hot air, the luminosity increased until 9 minutes of frying and then remained constant. 
The evolution of this parameter could be explained considering that luminosity depends on the amount of free water present on the surface favouring the reflexion of light (Hunt, 1080). In this way, the greater and faster surface dehydration during the initial stages of deep-oil frying (Heredia et al., 2010) implied a loss of luminosity in unpretreated and frozen samples. Moreover, deep-oil frying caused a darkening

170 reducing $L^{*}$ more than under hot air-frying conditions. In contrast in blanched samples,

$171 L^{*}$ initially increased during hot-air and in deep-oil frying as a consequence of the 172 greater presence of liquid phase (water) along frying than other samples (Heredia et 173 al., 2010).

174 Figure 2 shows the evolution of coordinates $a^{*}$ and $b^{*}$ during frying. In general, frying produced an increase in both coordinates. With regards to coordinate $a^{*}$, deep-oil frying caused a greater increase in the $a^{*}$ coordinate than hot-air frying especially in unpretreated samples. This phenomenon could suggest that air-frying decreases acrylamide generation, a carcinogenic compound directly related to the increase of $a^{*}$ (Gökmen \& Senyuva, 2006), compared to deep-oil frying conditions. The measurement of the parameter $a^{*}$ is used to determine the optimal frying point of fried products. In general, high values of $\mathrm{a}^{*}$ are not desirable, which means that positive values are not recommendable since they would indicate an orange tonality as a consequence of non enzymatic browning (the product will be too fried). Values between 0 and -5 of $a^{*}$ coordinate and values of $b^{*}$ coordinate higher than 10 are generally considered an optimal tonality for French fries (Krokida et al., 2001c).

Regarding the pre-treatment effect, different results are observed depending on the type of frying. In deep-oil frying, unpretreated and blanched samples showed a higher increase in the $a^{*}$ parameter than frozen samples. However, in hot air-frying, unpretreated potato strips showed the lowest increase of $a^{*}$, even reaching negative values during the 27 first minutes of the process.

191 Changes in coordinate $\mathrm{b}^{*}$ are not as remarkable as those in coordinate $\mathrm{a}^{*}$ considering 192 the kind of frying, although again deep-oil fried samples showed higher differences in 
the increment in $b^{*}$ than hot-air fried ones. Pretreatment also affected the parameter $b^{*}$ in a different way according to the type of frying. The higher the value of coordinate $b^{*}$, the greater the content of yellowness and this colour is desirable in fried products. According to this, better yellowness was obtained for unpretreated samples obtained by deep-oil frying followed by the frozen samples and then by the blanched ones. In hot-air frying, differences were lower and samples showed the opposite behaviour. The difference between colour coordinates in both frying methods is even higher when values are compared after 16 minutes of frying, maximum frying time in deep-oil frying. At this point in the process, the increase of $a^{*}$ for hot-air frying is negative and close to zero. This fact corroborates the lowest speed of physicochemical changes associated with mass and heat transfer in hot air-frying in comparison with traditional frying (Heredia et al., 2010).

In summary, deep-oil frying tends to increase the darkness of the samples in comparison to hot-air frying, especially in frozen samples. In fact, they showed a whiter colour before frying as a consequence of freezing. In contrast, hot-air frying implied an increase in luminosity or a null change despite requiring the longest treatment time.

Figure 3 shows the evolution of chrome $\left(C^{*}\right)$ and hue $\left(h^{*}\right)$ of the French fries as a function of frying time and pre-treatment for both frying methods. It can be observed that deep-oil fried samples showed higher $\mathrm{C}^{*}$ than hot-air fried ones, and the influence of the pre-treatment was only significant in deep-oil frying. Concretely, frozen potatoes showed lower values of $C^{*}$ than the others. With regards to hue $\left(h^{*}\right)$, the type of frying did not greatly affect $h^{*}$ values. However, it was remarkable that frozen samples showed the lowest value of $h^{*}$ in deep-oil frying. These results, along with changes in chrome, indicate a greater change of colour in frozen samples than in the other cases, especially in deep-oil frying.

As has been mentioned before, high values of coordinate $a^{*}$, and consequently high values of $h^{*}$, are related to high values of acrylamide content as a consequence of browning (Becalski et al., 2003; Haase et al., 2003; Pedreschi et al., 2006). These 
221 results suggest that hot air frying, with or without a blanching pre-treatment, could be a

222 healthier frying method since it slows down the kinetics of acrylamide formation and reduce the oil intake in the final product. However, to confirm this it would be necessary to determine the acrylamide content in the different studied conditions. The crusty texture of fried products is mainly characterised by the formation of a surface crust. This is also the parameter which is most appreciated by consumers. This crusty texture is a consequence of changes in the external layers of the product at a cellular level. These physicochemical changes include the physical damage caused by cutting the product, the formation of a rough layer with a release of intracellular material, starch gelatinization, protein denaturalization, water evaporation, expansion and tissue browning and finally oil ingress (Bouchon, Hollins, Pearson, Pyle, \& Tobin, 2001).

Figure 4 shows the evolution of maximum force $(\mathrm{N})$ during deep-oil and hot-air frying. This variable permits study not only of the softening of the vegetable tissue during the first minutes of the process, but also the development of the crust over time. As can be observed, in general, samples showed an initial stage of softening or firmness loss from the maximum value of firmness registered at time zero, followed by a second stage where maximum force tended to increase as the surface crust appeared. However, it is remarkable that the kind of frying affected the first stage of softening. In deep-oil frying a sharp decrease of the maximum force was produced in the first two minutes, which is related to a fast gelatinization of surface starch, characteristic of deep-oil frying, along with the partial denaturalization of proteins (Bouchon et al., 2001); while in hot-air frying the firmness loss took place in a more gradual way, reaching a minimum value between 15-21 minutes depending on the pre-treatment applied. Another difference is that crust formation started to appear earlier in the deepoil fried potatoes (from 2 min. on), due to the high evaporation rate, than in the hot-air

247 fried ones (from $18 \mathrm{~min}$. on). It is important to point out that the transition from the first stage (softening) to the second one (crust formation) takes place when the minimum 
249 force value is achieved. At this moment, water content in the samples ranging from 60-

$25062 \%$ independently of the frying method and the pretreatment applied (Heredia et al., $2512010)$.

252 With regards to the influence of the applied pretreatment in both types of frying it is observed that frozen potatoes had greater firmness at the end of the process. The higher consistency of their crust could be due to the fat coating, since they are pre-fried with an initial fat content of $3 \%$, according to the manufacturer. Unpretreated and blanched French fries showed a similar tendency in mechanical behaviour, although blanched potatoes tend to show a less crunchy surface crust.

\section{Conclusions}

260

The kinetic of mechanical and optical changes was strongly dependent on the frying method, being faster in deep-oil frying. Air-frying caused the lowest increase in the $a^{*}$ coordinate, which suggests that this new kind of frying could considerably reduce the amount of acrylamide in French fries. Regarding to texture, results show that it is possible to obtain French fries with similar textural features even if air-frying slows down the kinetic of mechanical changes compared to deep-frying,

\section{AKNOWLEDGMENTS}

Authors would like to thank to the Universitat Politècnica de València (PAID-06-092876) for the financial support given to this investigation.

\section{REFERENCES} prefried potatoes. Journal of Food Science, 65, 476-479. 
Amrein, T.M. Schönbächler, B., Escher \& F. Amadò, R. (2004). Acrylamide in gingerbread: Critical factors for formation and possible ways for reduction. Journal of Agricultural and Food Chemistry, 52(13), 4282-4288.

Becalski, A., Lau, B. P. Y., Lewis, D. \& Seaman, S. W., (2003). Acrylamide in foods: Occurrence, sources, and modeling. Journal of Agricultural and Food Chemistry, 51(3), 801-802.

Bouchon, P., Hollins, P., Pearson, M., Pyle, D.L.\& Tobin, M.J. (2001). Oil distribution in fried potatoes monitored by infrared microspectroscopy. Journal of Food Science, 66, 918-923.

Bourne, M.C. (2002). Food texture and viscosity: concept and measurement. Ed. Academic Press. Inc.

Debnath, S., Rastogi, N.K., Krishna, G.\& Lokesth, B.R. (2009). Oil partitioning between surface and structure of deep-fat fried potato slices. LWT - Food Science and Technology, 42 1054-1058.

Dueik, V., Robert, P.\& Bouchon, P. (2010). Vacuum frying reduces oil uptake and improves the quality parameters of carrot crisps. Food Chemistry, 119(3), 11431149.

Garayo, J. \& Moreira, G. (2002). Vacuum frying of potato chips. Journal of Food Engineering, 55(2), 181-191.

Gökmen, V., Palazoglu, T.K.\& Senyuva, H.Z. (2006). Relation between the acrylamide formation and time-temperature history of surface and core regions of French fries. Journal of Food Engineering, 77(4), 972-976.

Gökmen, V. \& Senyuva, H.Z., (2007). Study of colour and acrylamide formation in coffee, wheat flour and potato chips during heating. Food Chemistry, 99(2), 238-24.

Haase, N. U., Matthaus, B., \& Vosmann, K. (2003). Acrylamide formation in foodstuffs - Minimising strategies for potato crisps. Deutsche Lebensmittel Rundschau, 99, 87-90. 
Heredia, A., Castelló, M.L., Andrés, A. (2010). Air Frying: A new process for healthier French fried potatoes. Proceedings of the International Conference on Food Innovation.

Hunt, J. W. G. (1980). Measuring Color. Ellis Horwood Ltd. ISBN 0-7458-0125-0.

IARC, (1999). Some industrial chemicals. International Agency for Research on Cancer. IARC Monographis on the Evaluation of Carcinogenic Risks to Humans 60: 389-433.

Krokida, M. K. Oreopoulou, V. Maroulis, Z. B. \& Marinos-Kouris D. (2001 a). Effect of osmotic dedhydration pretreatment on quality of French fries. Journal of Food Engineering, 49(4), 339-345.

Krokida, M. K., Oreopoulou, V., Maroulis, Z. B., \& Marinos-Kouris, D. (2001b). Effect of pre-treatment on viscoelastic behaviour of potato strips. Journal of Food Engineering, 50, 11-17.

Krokida, M.K., Oreopoulou, V, Maroulis, Z.B.\& Marinos-Kouris, D. (2001c). Colour changes during deep fat frying. Journal of Food Engineering, 48(3), 219-225.

Mateos, M. (2003). Papa prefrita congelada (Doc.A-15); Estudio 1. EG.33.7, Componente A; Préstamo BID 925/OC-AR. Pre II. Coordinación del Estudio: Oficina de la CEPAL-ONU. En Bs.As., a solicitud de la Secretaría de la Política Económica, Ministerio de Educación de la Nación. Online. Date of consulting: $13 / 04 / 2011$. http://www.iica.int/Esp/regiones/sur/argentina/Documentos\%20de\%20la\%200fi cina/Papa prefrita-congelada.pdf

Liu, E.Z., Scanlon, M.G. (2007). Modeling the effect of blanching conditions on the texture of potato strips. Journal of Food Engineering, 81(2), 292-297.

Mai Tran T.T., Dong Chen, X. \& Southern, C. (2007); Reducing oil content of fried potato crisps considerably using a 'sweet' pre-treatment technique. Journal of Food Engineering, 80 (2) 719-726. 
Moreira, R. G. \& Barrufet, M.A. (1998). A new approach to describe oil absorption in fried foods: a simulation study. Journal of Food Engineering, 35, 1-22.

Moyano, P.C., Ríoseco, V.K. \& González, P.A. (2002). Kinetics of crust color changes during deep-fat frying of impregnated French fries. Journal of Food Engineering, 54(3), 249-255.

$\mathrm{Ni}, \mathrm{H}$. \& Datta, A.K. (1999). Moisture, oil and energy transport during deep-fat frying of food materials. Transactions of I Chem. Engr. Part C: Food and Bioproducts processing, 77, 194-204.

Pedreschi, F., Moyano, P., Kaack, K. \& Granby, K. (2005). Color changes and acrylamide formation in fried potato slices. Food Research International, 38, 19.

Pedreschi, F., Kaack, K., \& Granby, K. (2006). Acrylamide content and colour development in fried potato strips. Food Research International, 39(1), 40-46.

Song, X., Zhang, M., \& Mujumdar, A. S. (2007). Effect of vacuum-microwave predrying on quality of vacuum-fried potato chips. Drying Technology, 25, 2021-2026.

Taubert, D., Harlfinger, S., Henkes, L., Berkels, R.\& Schomig, E. (2004). Influence of processing parameters on acrylamide formation during frying of potatoes. Journal of Agricultural Food Chemistry, 50, 4998-5006. 
Table captions:

350 Table 1. CIEL* $a^{*} b^{*}$ coordinates of raw, frozen and blanched potato strips at the

351 beginning of the frying process.

352

353 Figure captions:

354 Figure 1. Evolution of luminosity, with respect to initial value $\left(L^{*}-L^{*} 0\right)$, versus time in 355 unpretreated, blanched and frozen French fries fried submitted to deep-oil $(\bullet, \boldsymbol{\Delta}$ and

356 respectively) or air frying $(\diamond, \Delta$ and $O$, respectively).

357 Figure 2. Evolution of chromatic parameters $a^{*}$ and $b^{*}$, with respect to initial value ( $a^{*}$ $358 a^{*}{ }_{0} ; b^{*}-b^{*}{ }_{0}$ ), versus time in unpretreated (control), blanched and frozen French fries 359 fried submitted to deep-oil ( $\bullet, \Delta$ and $\bullet$, respectively) or air frying $(\diamond, \Delta$ and $\mathrm{O}$, 360 respectively).

361 Figure 3. Evolution of chrome $\left(\mathrm{C}^{*}\right)$ and hue $\left(\mathrm{h}^{*}\right)$ versus time in unpretreated (control), 362 blanched and frozen French fries fried submitted to deep-oil ( $\bullet, \boldsymbol{\Delta}$ and $\bullet$, respectively) or air frying $(\diamond, \Delta$ and $O$, respectively).

364 Figure 4. Evolution of the Maximum Force $(\mathrm{N})$ versus time in unpretreated (control), blanched and frozen French fries fried submitted to deep-oil $(\bullet, \boldsymbol{\Delta}$ and $\bullet$, respectively) or air frying $(\diamond, \Delta$ and $\mathrm{O}$, respectively). 
369 Table 1. Moisture content, reducing sugars content (\% wet basis) and CIEL*a* $\mathrm{b}^{*}$ 370 coordinates of raw, frozen and blanched potato strips at the beginning of the frying 371 process $(n=3)$.

\begin{tabular}{lccc} 
& Raw & Blanched & Frozen \\
\hline Moisture (\%) & $82.5(0.2) \%^{\mathrm{a}}$ & $83.1(0.4)^{\mathrm{a}} \mathrm{a}^{\mathrm{a}}$ & $79.7(0.5) \%^{\mathrm{ab}}$ \\
Reducing sugars (\%) & $0.07(0.03)^{\mathrm{a}}$ & $0.05(0.02)^{\mathrm{b}}$ & $0.09(0.02) \%^{\mathrm{a}}$ \\
$\mathrm{L}^{*}$ & $61.9(1,6)^{\mathrm{a}}$ & $52(3)^{\mathrm{a}}$ & $71.90(1,09)^{\mathrm{ab}}$ \\
$\mathrm{a}^{*}$ & $-4.2(0,8)^{\mathrm{a}}$ & $-3.79(0,12)^{\mathrm{b}}$ & $-2.5(0,5)^{\mathrm{b}}$ \\
$\mathrm{b}^{*}$ & $14.5(1,9)^{\mathrm{a}}$ & $4(3)^{\mathrm{b}}$ & $10.4(0,4)^{\mathrm{b}}$ \\
$\mathrm{h}^{*}$ & $92(3)^{\mathrm{a}}$ & $126(3)^{\mathrm{b}}$ & $104(3)^{\mathrm{b}}$ \\
$\mathrm{C}^{*}$ & $14(1,9)^{\mathrm{a}}$ & $5.9(1,9)^{\mathrm{b}}$ & $9.9(0,6)^{\mathrm{b}}$
\end{tabular}




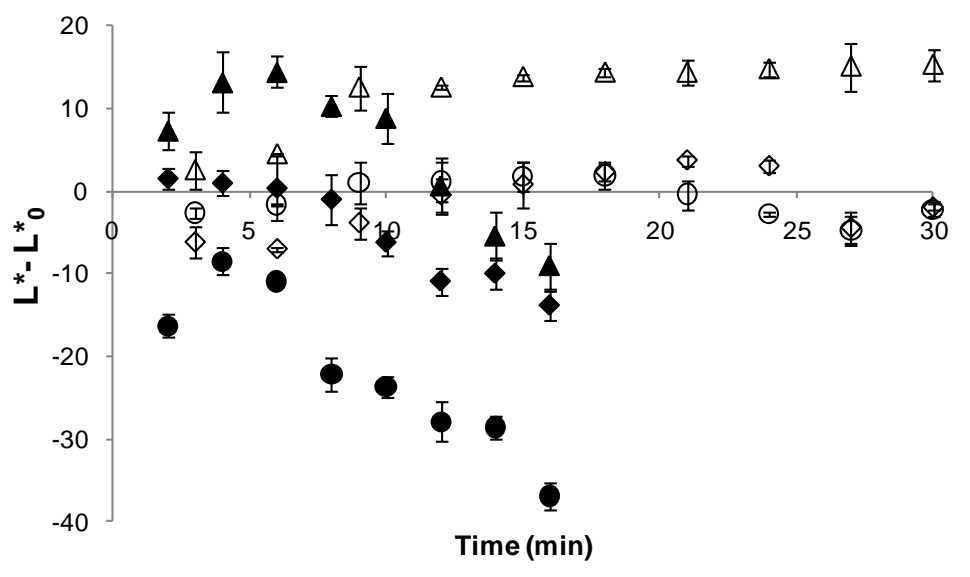

Figure 1. 
379


380

381

Figure 2.

382 
383
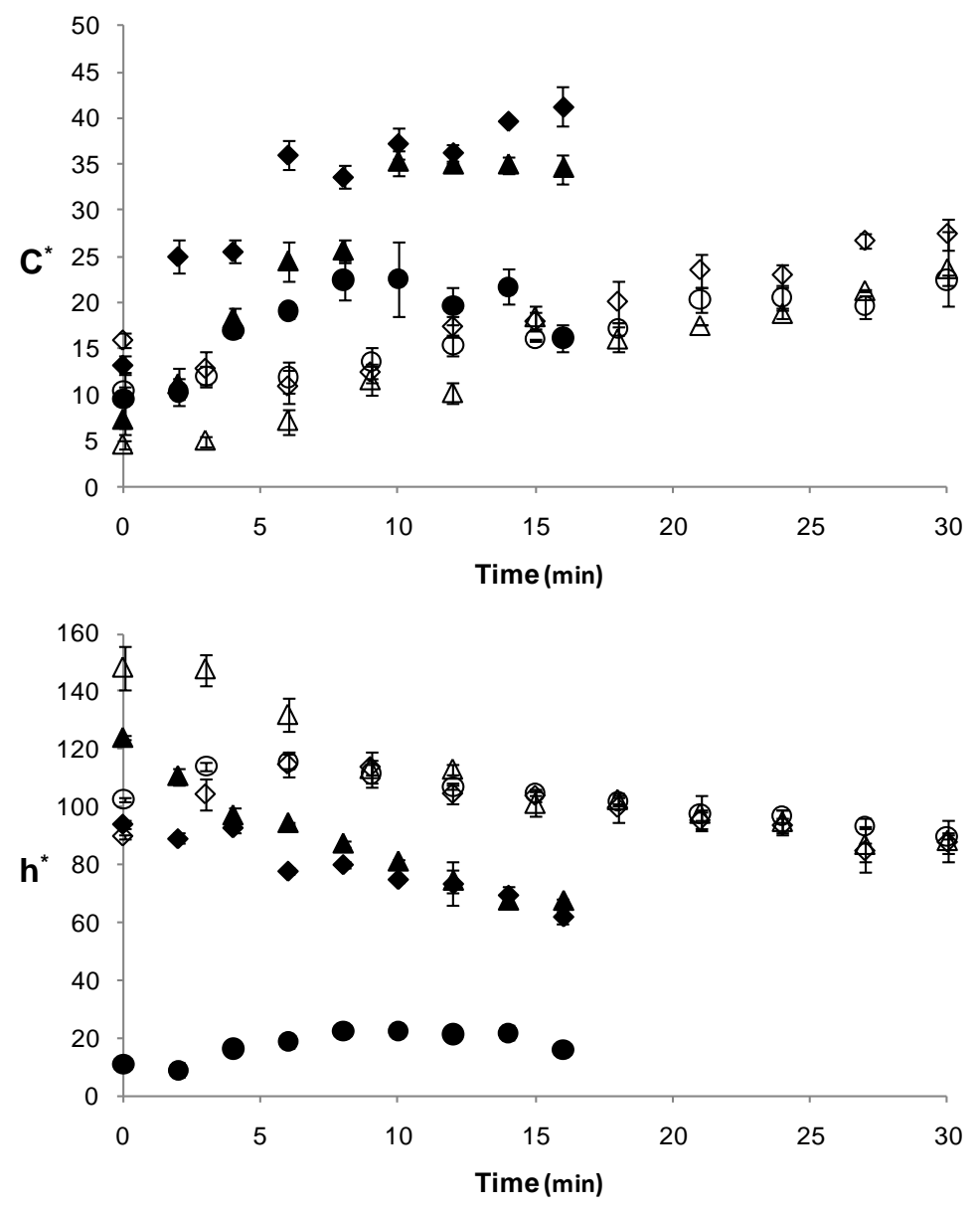

Figure 3.

386 

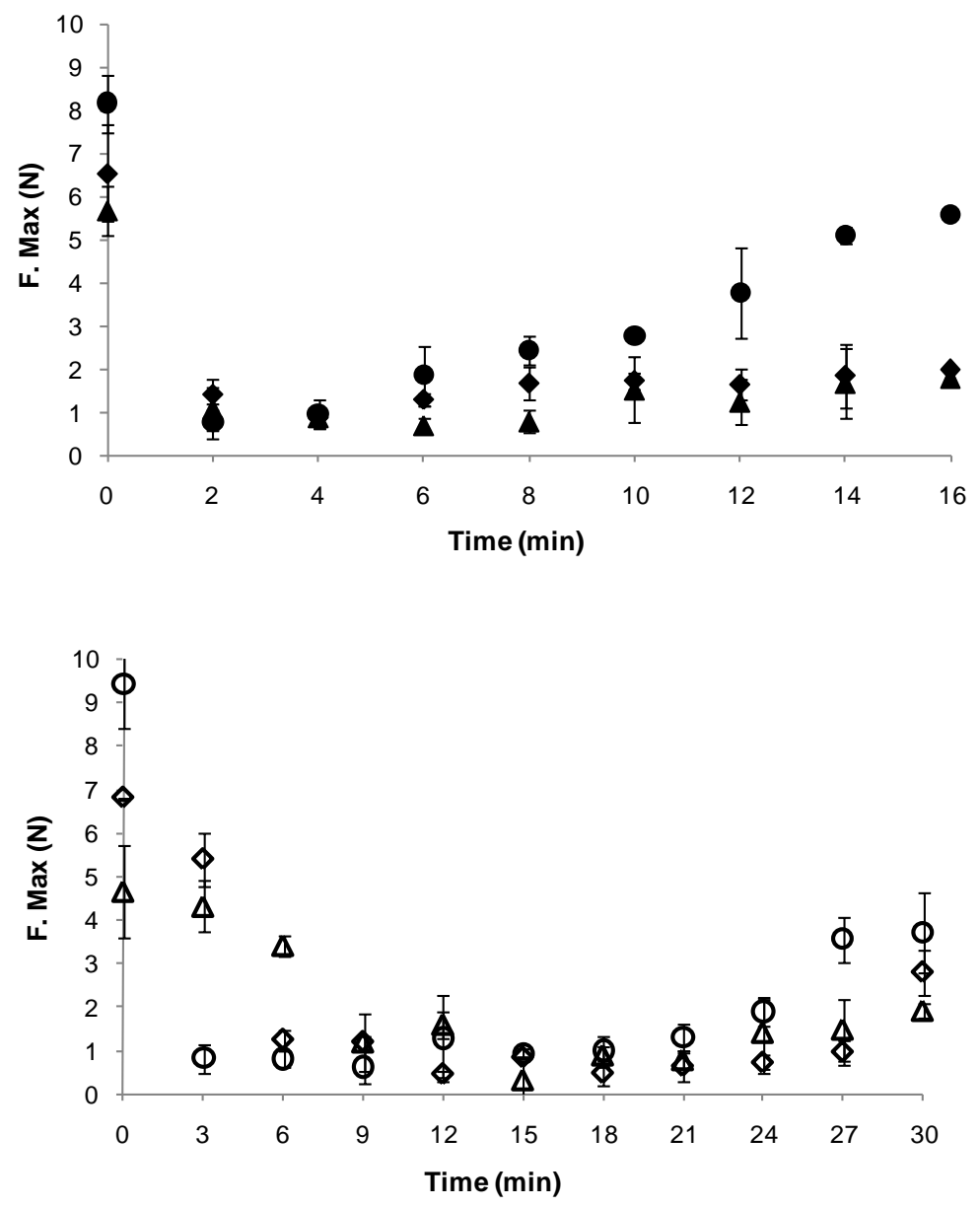

Figure 4.

390 